\title{
Phase II study of gefitinib in combination with docetaxel as first-line therapy in metastatic breast cancer
}

\author{
F Ciardiello', T Troiani', F Caputo ${ }^{2}$, M De Laurentiis' ${ }^{2}$, G Tortora ${ }^{2}$, G Palmieri', F De Vita', MR Diadema', \\ M Orditura', G Colantuoni ${ }^{3}$, C Gridelli $^{3}$, G Catalano', S De Placido ${ }^{2}$ and AR Bianco ${ }^{2}$ \\ 'Cattedra di Oncologia Medica, Dipartimento Medico-Chirurgico di Internistica Clinica e Sperimentale 'F Magrassi e A Lanzara', Seconda Università degli \\ Studi di Napoli, Via S Pansini 5, 80131 Naples, Italy; ${ }^{2}$ Cattedra di Oncologia Medica, Dipartimento di Endocrinologia e Oncologia Molecolare e Clinica \\ Università degli Studi di Napoli 'Federico II', Naples, Italy; ${ }^{3}$ Divisione di Oncologia Medica, Ospedale SG Moscati, Avellino, Italy
}

We have evaluated the activity and safety of gefitinib, a small-molecule epidermal growth factor receptor (EGFR) tyrosine kinase inhibitor, in combination with docetaxel as first-line treatment of women with metastatic breast cancer (MBC). In total, $4 \mathrm{I}$ patients with $\mathrm{MBC}$ were enrolled in a first-line combination therapy study with oral gefitinib $\left(250 \mathrm{mg} \mathrm{day}^{-1}\right)$ and intravenous docetaxel ( $75 \mathrm{mg} \mathrm{m}^{-2}$, the first 14 patients; or $100 \mathrm{mg} \mathrm{m}^{-2}$, the following 27 patients, on day I of a 3-week cycle). Out of 41 patients, 38 received at least one cycle of therapy. There were no differences in activity or tolerability between the two docetaxel doses. G3/4 toxicities were neutropenia (49\%), diarrhoea (10\%), acne-like rash (5\%), and anaemia (2\%). Complete plus partial responses $(C R+P R)$ were observed in 22 out of 4 I patients with a $54 \%$ response rate ( $95 \%$ confidence interval (Cl) $45-75 \%)$. The 22 patients that achieved a response following six cycles of docetaxel plus gefitinib continued gefitinib monotherapy (median duration, 24 weeks; range, $2-108+$ weeks). Two patients with PR following combination therapy achieved a CR during gefitinib monotherapy. Complete plus partial responses correlated with oestrogen receptor (ER) status, since they occurred in 19 out of 27 (70\%) patients with ER-positive tumours as compared to three out of $14(21 \%)$ patients with ER-negative tumours $(P=0.0 \mathrm{I})$. British Journal of Cancer (2006) 94, 1604- 1609. doi:I0.1038/sj.bjc.6603 I4I www.bjcancer.com

Published online 9 May 2006

(c) 2006 Cancer Research UK

Keywords: metastatic breast cancer; taxanes; small-molecule EGFR tyrosine kinase inhibitors; combination therapy

Breast cancer is the most common malignancy among women and is the second leading cause of death for cancer in the Western countries after lung cancer. Although only a minority of patients is initially diagnosed with metastatic breast cancer (MBC), approximately $30-40 \%$ of all patients with early breast cancer, which are treated with curative intent will ultimately develop metastatic disease. Survival rates for MBC patients have been improved in recent years. However, despite advances in therapy, MBC largely remains an incurable disease and after documentation of metastasis the median survival time is approximately 2 years (Greenberg et al, 1996; Hortobagyi, 2002; Mincey and Perez, 2004). Docetaxel is a first-generation taxane that has a wide spectrum of antitumour activity and a number of unique characteristics compared to other chemotherapeutic agents, including the other taxane paclitaxel (Ringel and Horwitz, 1991; Riou et al, 1992; Bissery et al, 1995; Montero et al, 2005). Docetaxel is active in MBC patients (Nabholtz et al, 1999; Sjöström et al, 1999; Bonneterre et al, 2002; O'Shaughnessy et al, 2002; Tabernero et al, 2004; reviewed in Montero et al, 2005). In phase II studies docetaxel treatment determines response rates (RR) of approximately 38 $68 \%$ (reviewed in Nabholtz and Gligorov, 2005). In phase III studies, when it is used as single agent in previously untreated women with $\mathrm{MBC}$, docetaxel determines $\mathrm{RR}$ ranging between 30

Correspondence: Dr F Ciardiello;

E-mail: fortunato.ciardiello@unina2.it

Received 19 December 2005; revised 3 April 2006; accepted 3 April 2006; published online 9 May 2006 and $48 \%$ (reviewed in Montero et al, 2005), whereas docetaxel in combination with an anthracycline determines a RR of $42-59 \%$ with a time to progression (TTP) ranging between 6.3 and 10.5 months (reviewed in Montero et al, 2005).

There is a large body of scientific evidence that the epidermal growth factor receptor (EGFR) pathway contributes to a number of processes involved in cancer cell proliferation, survival and invasion rendering it an attractive target for anticancer therapy (Ciardiello and Tortora, 2001). Studies in genetically modified mice have suggested a role for the EGFR pathway in mammary development and neoplastic transformation (Luetteke et al, 1999). In fact, overexpression of the EGFR ligand, transforming growth factor $\alpha$ (TGF $\alpha$ ), in the mammary epithelium results in mammary hyperplasias and carcinomas after a prolonged latency (Matsui et al, 1990; Sandgren et al, 1990). Overexpression of EGFR is found in $14-91 \%$ of breast cancer and this has been correlated with disease progression and poor prognosis (Klijn et al, 1992; Fox et al, 1994; Klijn et al, 1994; Salomon et al, 1995).

There are several agents in clinical development that target the EGFR, and two of the most effective pharmacologic approaches currently under clinical investigation are small-molecule EGFR tyrosine kinase inhibitors and EGFR-blocking monoclonal antibodies (Ciardiello and Tortora, 2001; Grunwald and Hidalgo, 2003; Mendelsohn and Baselga, 2003). Gefitinib (ZD1839, Iressa ${ }^{\mathrm{TM}}$ ) is an orally active, small-molecule, reversible EGFR tyrosine kinase inhibitor (Herbst et al, 2004). Preclinical studies have shown that gefitinib has a broad spectrum of antitumour activity including human breast cancer (Ciardiello et al, 2000). Further, the combination of gefitinib with different cytotoxic drugs including 
docetaxel potentiates the antitumour activity of these drugs (Ciardiello et al, 2000; Sirotnak et al, 2000). In this respect, we have demonstrated that gefitinib is active and restores the sensitivity to docetaxel or to paclitaxel in multidrug-resistant, taxane-resistant human breast cancer cells (Ciardiello et al, 2002). Gefitinib is active also in breast cancer cell models which are resistant to endocrine therapy (Nicholson et al, 2002; Knowlden et al, 2003; Shou et al, 2004). In this respect, it has been shown that the EGFR-dependent autocrine pathway plays a key role both in intrinsic or de novo resistance to tamoxifen in ER positive, HER2 overexpressing MCF-7 breast cancer cells and in the acquired resistance to tamoxifen in tamoxifen-treated MCF-7 cells (Nicholson et al, 2002; Knowlden et al, 2003; Shou et al, 2004). In both experimental systems, gefitinib has a significant antitumour activity (Nicholson et al, 2002; Knowlden et al, 2003; Shou et al, 2004).

Based on these preclinical data, we have performed a phase II study of the combination of gefitinib and docetaxel as first-line treatment in patient with MBC. We have evaluated the safety, the tolerability profile and the clinical activity of gefitinib, $250 \mathrm{mg}$ daily, in combination with docetaxel on a 3 weeks schedule at two different doses $\left(75 \mathrm{mg} \mathrm{m}^{-2}\right.$ and $\left.100 \mathrm{mg} \mathrm{m}^{-2}\right)$.

\section{PATIENTS AND METHODS}

\section{Patients}

Female patients aged 18 years or older with histologically confirmed $\mathrm{MBC}$ who had not previously received chemotherapy, hormonal therapy, immunotherapy or treatment with monoclonal antibodies for metastatic disease were eligible for this study. Patients were required to have measurable disease as defined in the Response Evaluation Criteria in Solid Tumours (RECIST) criteria and adequate general health status (Eastern Cooperative Oncology Group, ECOG, Performance Status, PS, 0-1). Patients who had received prior radiotherapy within the 2 weeks before entry into the trial were ineligible. Any patient with a history of a second malignancy within 5 years, with the exception of curatively treated basal cell carcinoma of the skin or cervical cancer in situ, was ineligible. Absence of severe and uncontrolled systemic disease such as unstable respiratory, cardiac, hepatic or renal disease was required. The following laboratory parameters documented within 1 week before enrollment were required: absolute neutrophil count (ANC) greater than $1.5 \times 10^{9} 1^{-1}(\mathrm{~L})$ and platelets greater than $100 \times 10^{9} 1^{-1}$; ALT or AST $\leqslant 1.5$ times the upper limit of normal range (ULRR) and alkaline phosphatase of $\leqslant 2.5$ times the ULRR; bilirurbin within normal limits and creatinine of $\leqslant 1.5$ times the ULRR. Women of childbearing potential should have had a negative pregnancy test before enrollment and were advised to practice appropriate contraception while on study. Patients were excluded from treatment with phenytoin, carbamazepine, barbiturates or rifampicin while on protocol. Concomitant bisphosphonates were allowed for patients with bone metastasis. This study was conducted in accordance with the Declaration of Helsinki and the study protocol was reviewed and approved by the local Research Ethics Committees (University of Naples and Ospedale SG Moscati, Avellino). Before study entry, each patient signed a written informed consent. Patients were enrolled between August 2002 and May 2004. Data analysis has been performed 12 months after the last patient had been enrolled (31 May 2005). The median follow-up was 23 months (range, 12-34 months).

\section{Treatment plan}

Docetaxel and gefitinib combined treatment was planned for initial three cycles. Patients who had a clinical response (i.e. patients with complete response (CR), partial response (PR), or stable disease (SD)) after the first three clycles received additional three cycles of combination therapy. Gefitinib was continued as monotherapy only for patients who had CR or PR after the end of six cycle of combination therapy and this treatment was given until disease progression, unacceptable toxicity or withdrawal of consent. Patients received gefitinib, $250 \mathrm{mg}$, orally, once daily, continuously, in the morning at approximately the same time each day. The initial docetaxel dose was $75 \mathrm{mg} \mathrm{m}^{-2}$ as intravenous (i.v.) administration for $60 \mathrm{~min}$, every 3 weeks. Docetaxel dose was escalated to $100 \mathrm{mg} \mathrm{m}^{-2}$ i.v. administration for $60 \mathrm{~min}$, every 3 weeks, after the first 14 patients completed the planned treatment without the occurrence of any unacceptable toxicity as defined by an event that required dosage reduction or interruption in more than three patients. Patients received three doses of prophylactic dexamethasone, $8 \mathrm{mg}$ i.m., every $12 \mathrm{~h}$ starting the $24 \mathrm{~h}$ before docetaxel infusion. Toxicities were graded according to the National Cancer Institute Common Toxicity Criteria (NCI-CTC), Version 2.0. Dose interruption was planned for NCI-CTC grade 3 and 4 toxicity related to gefitinib. Once the toxicity decreased in severity to grade 1 , the patient may have continued on the assigned dose. Repeated dose interruptions were allowed as required, for a maximum of 14 days on each occasion. No dose reduction was allowed. If toxicity recurred after drug rechallenge, and further interruptions were considered insufficient to manage the toxicity, gefitinib discontinuation was required and patients were withdrawn from the trial. To manage docetaxel-related toxicity, treatment with docetaxel was delayed by no more than 2 weeks. If treatment was delayed for either haematologic or nonhaematologic toxicity for more than 2 weeks, the patients were withdrawn from the trial. In case of grade 2 neutropenia and of grade 3 thrombocytopenia, treatment with docetaxel was delayed until toxicity was resolved to grade 1 or less. In case of repeated delays due to grade 2 neutropenia, the dose of docetaxel could be reduced to $75 \mathrm{mg} \mathrm{m}^{-2}$ or to $50 \mathrm{mg} \mathrm{m}^{-2}$, for all the subsequent infusions in patients who received, respectively, the initial docetaxel dose of $100 \mathrm{mg} \mathrm{m}^{-2}$ or of $75 \mathrm{mg} \mathrm{m}^{-2}$. If further delays were required the patients would have been withdrawn from the trial. The treatment with docetaxel was planned to be discontinued with patients taken off study in case of grade 4 neutropenia for 7 days or more and/or grade 3-4 neutropenia with axilar fever $\geqslant 38^{\circ} \mathrm{C}$ or documented infection.

\section{Patient clinical evaluation and assessment of response}

Before study entry, a complete medical history, physical examination including performance status, height, weight and vital signs, electrocardiogram, urine analysis, pregnancy test if indicated, and radiographic tumour assessment within 21 days before start treatment were performed. Patients were evaluated at the start of each cycle during the combination treatment with physical examination, laboratory tests while adverse reactions were documented every week, whereas radiographic tumour assessment was repeated at the end of cycles 3 and 6 . During gefitinib monotherapy, physical examination, haematology, biochemistry, evaluation of adverse events and radiographic tumour assessment were performed every 6 weeks until patient progression or trial closure.

\section{Study end points}

The primary objective of this trial was to evaluate the activity of oral gefitinib administration in combination with docetaxel as first-line treatment in patients with $M B C$ by estimating the objective tumour response rates ( $\mathrm{CR}$ and $\mathrm{PR}$ ) according to the RECIST criteria (Therasse et al, 2000). Secondary objectives were to estimate the disease control rate (CR, PR plus SD), the TTP, the overall survival (OAS) and to further characterise the safety and tolerability profile of gefitinib, $250 \mathrm{mg}$ daily dose, alone and in combination with every 3 weeks i.v. docetaxel. Responses were evaluated by the investigators and were confirmed after 4 weeks. 


\section{Statistical analysis}

This was an open, noncomparative, two centre, phase II trial. The Fleming's method was used to calculate the number of patients required (Fleming, 1982). A sample size of 41 patients was calculated as sufficient to give an $80 \%$ probability of rejecting a baseline RR of $35 \%$ with an exact $5 \%$ one-sided significance test when the true response is at the clinically relevant rate of $55 \%$. The hypothesis that the $\mathrm{RR}$ is equal or less than the baseline was considered to be rejected if 20 or more responses were observed in the 41 patients. All patients that were enrolled and received trial treatment were considered as the intention-to-treat (ITT) population. The analysis population for all efficacy end points were the ITT population. Response rates were estimated using the exact two-sided type $95 \%$ confidence interval (CI) method based on the binomial proportions. The association between the different clinicopathologic characteristics and responses to treatment was studied by the use of contingency tables. Statistical significance was evaluated by the Pearson $\chi^{2}$ test. Duration of response, TTP and OAS were estimated by the Kaplan-Meier method (Kaplan and Meier, 1958).

\section{RESULTS}

\section{Patients characteristics}

A total of 41 female patients with MBC, who had not previously received chemotherapy or hornomotherapy for metastatic disease, were enrolled in this study. The clinical characteristics of these women are listed in Table 1 . The median age was 58 years; most women had a good ECOG PS, in particular 39 patients (95\%) had a PS 0 at screening, while only two patients had a PS $1(5 \%)$. The prevalent histotype was ductal infiltrating carcinoma (37 out of 41 patients, $90 \%)$, while four patients $(10 \%)$ had a lobular infiltrating carcinoma. The majority of women $(83 \%)$ had visceral disease. Five of the patients on study (12\%) had HER-2 $3+$ at the immunohistochemistry screening of the primary tumour, $22(54 \%)$ patients had a HER-2-negative tumour, whereas the HER-2 status of $14(34 \%)$ patients was not known. Tumours in 27 patients were oestrogen receptor-positive (66\%) and in 14 cases (34\%) were ER negative. Most patients had received, in the adjuvant setting, prior chemotherapy and hormonotherapy (tamoxifen, $20 \mathrm{mg}$ daily planned for 5 years) (73 and 59\%, respectively). The 24 patients that had received adjuvant hormonotherapy therapy were treated with tamoxifen for 6 months to 5 years (median, 3 years). Of the patients, $22(54 \%)$ had been treated with antracyclines and six patients $(15 \%)$ had received a taxane in the adjuvant setting.

\section{Toxicity}

A total of 216 cycles (median, 5.2. cycles; range, 1-6) of docetaxel infusions were administrated. None of the patients had docetaxel dose delay and no woman developed toxicity requiring dose adjustment of docetaxel. The first 14 patients were treated for up to six cycles with the combination of docetaxel $\left(75 \mathrm{mg} \mathrm{m}^{-2}\right.$ dose $)$ and gefitinib. Since no major toxicity occurred, as per protocol planning, the following 27 patients enrolled in this study were treated with combination of docetaxel $\left(100 \mathrm{mg} \mathrm{m}^{-2}\right.$ dose $)$ and gefitinib. There were no differences in grade and profile of toxicity between the two docetaxel doses. Therefore, toxicity data are presented on the whole 41 patient population. Thirty eight patients received at least one cycle of combination therapy with docetaxel and gefitinib. In general, treatment was well tolerated. The worst grades of treatment-related toxicity for the 41 patients are listed in Table 2. Three patients developed, despite the required premedication with dexamethasone, hypersensitivity reactions after a few minutes of starting the first i.v. infusion of docetaxel. These women, who were never treated with gefitinib, were taken off
Table I Patient characteristics

\begin{tabular}{|c|c|c|}
\hline & \multicolumn{2}{|c|}{ Patients $(N=4 I)$} \\
\hline & $\mathbf{N}$ & $\%$ \\
\hline \multicolumn{3}{|l|}{ Age (years) } \\
\hline Median & \multirow{2}{*}{\multicolumn{2}{|c|}{$\begin{array}{c}58 \\
40-75\end{array}$}} \\
\hline Range & & \\
\hline \multicolumn{3}{|l|}{ ECOG performance status } \\
\hline 0 & 39 & 95 \\
\hline I & 2 & 5 \\
\hline 2 & 0 & 0 \\
\hline \multicolumn{3}{|l|}{ Histology } \\
\hline Ductal infiltrating carcinoma & 37 & 90 \\
\hline Lobular infiltrating carcinoma & 4 & 10 \\
\hline \multicolumn{3}{|l|}{ ER expression (IHC) } \\
\hline Positive & 27 & 66 \\
\hline Negative & 14 & 34 \\
\hline \multicolumn{3}{|l|}{ HER-2 expression (IHC) } \\
\hline $3+$ & 5 & 12 \\
\hline Negative & 22 & 54 \\
\hline Unknown & 14 & 34 \\
\hline \multicolumn{3}{|l|}{ Prior adjuvant therapy } \\
\hline Yes & 30 & 73 \\
\hline No & | | & 27 \\
\hline Prior adjuvant chemotherapy & 30 & 73 \\
\hline Prior adjuvant anthracyclines & 22 & 54 \\
\hline Prior adjuvant taxanes & 6 & 15 \\
\hline Prior adjuvant hormonotherapy (tamoxifen) & 24 & 59 \\
\hline \multicolumn{3}{|l|}{ Dominant sites of disease } \\
\hline Visceral & 34 & 83 \\
\hline Soft tissue (lymph nodes and bone sites) ${ }^{a}$ & 7 & 17 \\
\hline
\end{tabular}

a No patient had only bone metastases.

protocol and switched to a chemotherapy regimen without docetaxel. Haematologic toxicity was noted in the majority of patients during the combination treatment period with grade 3 or 4 neutropenia affecting $49 \%$ of patients. Neutropenia was the only grade 4 haematologic toxicity observed. No patients developed neutropenic fever. Grade 3 anaemia occurred in one patient. There was minimal thrombocytopenia. Nonhaematologic toxicities related to study treatment are also listed in Table 2. Gastrointestinal side effects such as nausea/vomiting or stomatitis were mild with only grade 1 or 2 toxicity recorded. Grade 3 diarrhoea occurred in four patients $(10 \%)$ and was controlled with loperamide administration. Only one patient with grade 3 diarrhoea refused further treatment after one cycle of combination therapy. Neuropathy affected $17 \%$ of patients and none exceeded grade 2 toxicity. Several patients developed asthenia, but only two with grade 3 toxicity. Abnormal values for ALT and/or AST were reported in 11 patients, but only in two patients reached grade 3 toxicity. Two patients had grade 3 acne-like rash after the first cycle of combination therapy. After 1 week of gefitinib treatment suspension and recover to grade 1 skin toxicity, treatment with gefitinib was restarted. In these two patients, the intensity of this skin reaction did not exceed grade 2 with the following cycles of combination treatment. However, two of the three patients who experienced grade 2 skin toxicity decided to withdraw their consent after one cycle of combination therapy and were switched to a different chemotherapy regimen. 
Table 2 Worst grade of toxicity for the 4 I patients

\begin{tabular}{|c|c|c|c|c|c|c|c|c|}
\hline \multirow{2}{*}{ Toxicity } & \multicolumn{8}{|c|}{ Grade } \\
\hline & \multicolumn{2}{|c|}{$\mathbf{I}$} & \multicolumn{2}{|c|}{2} & \multicolumn{2}{|c|}{3} & \multicolumn{2}{|c|}{4} \\
\hline Anaemia & 7 & 17 & 4 & 10 & । & 2 & 0 & \\
\hline Thrombocytopenia & 2 & 5 & 0 & & 0 & & 0 & \\
\hline Neutropenia & 12 & 29 & 4 & 10 & 6 & 15 & 14 & 34 \\
\hline Stomatitis & 2 & 5 & 2 & 5 & 0 & & 0 & \\
\hline Diarrhoea & 9 & 22 & 5 & 12 & 4 & 10 & 0 & \\
\hline Mucositis & 7 & 17 & 2 & 5 & 0 & & 0 & \\
\hline Pain & 1 & 2 & 0 & & 0 & & 0 & \\
\hline Fever & 2 & 5 & 5 & 12 & 0 & & 0 & \\
\hline Hypersensitivity ${ }^{a}$ & 0 & & 0 & & 3 & 7 & 0 & \\
\hline Neuropathy & 6 & 15 & I & 2 & 0 & & 0 & \\
\hline
\end{tabular}

aHypersensitivity reactions after few minutes of starting the first intravenous injection of docetaxel were observed in three patients, which, therefore, were never treated with gefitinib and which were switched to a chemotherapy regimen without docetaxel. Toxicities were recorded according to the National Cancer Institute Common Toxicity Criteria ( $\mathrm{NCl}-\mathrm{CTC})$ version 2.0.

\section{Clinical activity}

Of 41 patients enrolled in this study, three were never treated with gefitinib, because they had to stop the first adminstration of i.v. docetaxel on day 1 of the first cycle without receiving gefitinib due to hypersensitivity reactions to docetaxel. On an intention to treat analysis of the entire 41 patient population, major clinical responses were observed in 22 patients for an overall RR of $54 \%$ (CI, $45-75 \%$ ) (Table 3). Five CR and 17 PR were observed. Two of the 17 patients with PR following completing the six cycles of docetaxel-gefitinib combination therapy achieved a CR during gefitinib monotherapy. Six patients (14\%) had a SD and 13 patients (32\%) experienced disease progression. The 22 patients that achieved a response following six cycles of docetaxel plus gefitinib continued gefitinib monotherapy (median duration, 24 weeks; range, $2-108+$ weeks). Major responses (CR $+\mathrm{PR})$ were evaluated in correlation with all clinical and pathologic characteristics (listed in Table 1) of the patients. No significant correlation was observed between the achievement of a clinical response and any parameter which was evaluated, except for a statistically significant association between response to treatment and ER status (Table 4). In fact, in those patients with ER-positive tumours, CR + RP were observed in 19 out of $27(70 \%)$ patients, whereas among patients with ER-negative cancers the RR was three out of $14(21 \%)$ patients. If we consider only the 35 patients who were treated with gefitinib and docetaxel combination for at least two cycles of therapy, major clinical responses $(\mathrm{CR}+\mathrm{RP})$ were observed in 19 out of $23(82 \%)$ patients with ER-positive tumours, whereas among patients with ER-negative cancers the RR was three out of 12 (25\%). The median OAS in the entire population of 41 patients enrolled in this study could not be calculated at the time of the analysis for the low numbers of deaths occurred. The median TTP which was analysed on an intention to treat basis on the all 41 patients was 8.2 months. The median duration of response for responding patients was 6.5 months (range, 3-23.5+ months).

\section{DISCUSSION}

To our knowledge this is the first report on docetaxel and gefitinib combination as first-line treatment of patients with MBC. The results of this study suggest that treatment with docetaxel and gefitinib is an active and generally well-tolerated regimen in
Table 3 Response to therapy for the 4 I patients

\begin{tabular}{lrc}
\hline & \multicolumn{2}{c}{ Patients $(\mathbf{N}=\mathbf{4 I})$} \\
\cline { 2 - 3 } Response & $\mathbf{N}$ & $\%$ \\
\hline Overall response & 22 & 54 \\
$\quad$ Complete response (CR) & 5 & 12 \\
Partial response (PR) & 17 & 42 \\
Stable disease (SD) & 6 & 14 \\
Progressive disease (PD) & 13 & 32 \\
\hline
\end{tabular}

Among these 4 I patients, three were never treated with gefitinib, because they had to stop the first adminstration of i.v. docetaxel on day I of the first cycle before receiving gefitinib due to hypersensitivity reactions to docetaxel. Three additional patients refused further therapy after one cycle. Refusal was due to grade 3 diarrhoea in one patient and to grade 2 acne-like rash in the other two patients. For the intention to treat analysis, all six patients were recorded as patients with progressive disease

women with $\mathrm{MBC}$ who have not been previously treated for metastatic disease. Most of the toxicities observed were consistent with those expected when using docetaxel as single agent (reviewed in Montero et al, 2005). The most frequent G3/4 toxicity was neutropenia, although no febrile neutropenia or neutropenic infection occurred. Peripheral neuropathy and asthenia observed in this trial were also similar to those observed with single agent docetaxel given every 3 weeks (reviewed in Montero et al, 2005). The adverse events associated with gefitinib were diarrhoea and acne-like rash and were in line with the reported safety profile for this drug (Herbst et al, 2004). In particular, two patients experienced grade 3 skin toxicity. However, after 1 week of treatment suspension, gefitinib was restarted and the intensity of this skin reaction did not exceed grade 2 thereafter.

The RR reported in this trial are in a range which is comparable to those obtained when docetaxel is combined with antracyclines (reviewed in Montero et al, 2005). Several studies have been published on the combination of docetaxel with trastuzumab, the first therapeutic agent targeting the human epidermal growth factor receptor-2 (HER2) which has been used in breast cancer (Baselga et al, 1996). Trastuzumab is currently used in association 
Table 4 Correlation between ER positivity and major clinical responses $(C R+P R)$ to therapy

\begin{tabular}{lll}
\hline Responses & ER positive (27/4I patients) & ER negative (I4/4I patients) \\
\hline CR+PR (22/4I patients) & $19 / 27$ patients $(70 \%)$ & $3 / 14$ patients $(21 \%)$ \\
SD+PD (19/4I patients) & $8 / 27$ patients $(30 \%)$ & $11 / 14$ patients $(79 \%)$ \\
\hline
\end{tabular}

Pearson's $\chi^{2}$ test: $P=0.01$.

with several chemotherapy drugs, including taxanes, for women who have been selected for having HER2 overexpressing MBC. In particular, several phase II studies of trastuzumab in combination with docetaxel, as first- or as second-line treatment for patients with HER2 - overexpressing MBC, have been reported with RR ranging from 45 to $72 \%$ (Burris, 2001; Esteva et al, 2002; Montemurro et al, 2004; Tedesco et al, 2004). More recently, the results of a randomised phase II trial evaluating the activity and the efficacy of trastuzumab plus docetaxel in the first-line treatment of HER2 - overexpressing MBC patients have been reported (Marty et al, 2005). In this study, a $61 \% \mathrm{RR}$, a 11.7 months TTP and a 31.2 months median OAS have been observed.

A potentially interesting observation which emerges from our study is that a statistically significant association has been found between clinical response to gefitinib plus docetaxel treatment and ER status (Table 4). In fact, in those patients with ER-positive tumours, the RR is $70 \%$, whereas among patients with ER-negative cancers the RR is $21 \%$. The majority of patients who experienced SD or PD had ER-negative tumours. These clinical data may be explained by the recent experimental findings in MCF-7 human breast cancer cells, which are initially oestrogen-dependent for growth and sensitive to the antioestrogen tamoxifen. MCF-7 cells which are chronically cultured in the presence of tamoxifen generally become tamoxifen-resistant between 3 and 6 months (Nicholson et al, 2002; Knowlden et al, 2003). Tamoxifen-resistant MCF-7 cells exhibit markedly increased levels of EGFR and HER-2 as compared to tamoxifen-sensitive parental MCF-7 cells (Nicholson et al, 2002; Knowlden et al, 2003). Furthermore, these cells exhibit an increased dependence on EGFR signaling for proliferation and survival and they become extremely sensitive to gefitinib (Nicholson et al, 2002). Therefore, a possible interpretation for the findings of our study is that women with ER-positive-tumours, which have been treated chronically up to 5 years in the adjuvant setting with the antioestrogen tamoxifen, may have eventually developed a MBC in which the EGFR-driven pathway has become important for cancer cell growth and for such reason become sensitive to gefitinib. In this context, the EGFR signaling pathway which is upregulated in tamoxifen-resistant ER-positive breast cancer would be of critical relevance in the escape from the growth inhibition induced by the antioestrogen tamoxifen. The possibility that women with ER-positive breast cancer may be selected for the treatment with EGFR inhibitors is supported also by the preliminary results of a phase II study in which it has been investigated the activity and safety of gefitinib in patients with tamoxifen-resistant ER-positive breast cancer (Robertson et al, 2003). In this trial, $66 \%$ of patients with tamoxifen-refractory disease achieved a clinical benefit (PR plus SD) with gefitinib monotherapy, as compared to only $11 \%$ of patients with ERnegative disease. On the contrary, three phase II studies in unselected, heavily pretreated women with MBC have shown that gefitinib monotherapy has minimal clinical activity with $\mathrm{RR}$ ranging between 0 and 2\% (Albain et al, 2002; Baselga et al, 2005; von Minckwitz et al, 2005). However, a randomised phase II trial has recently shown that a short 4- to 6-weeks treatment with gefitinib monotherapy or with gefitinib plus the aromatase inhibitor anastrozole in postmenopausal breast cancer patients with ER-positive and EGFR-positive tumours before curative surgery determines PR in 12 out of 22 patients and in 14 out of 28 patients, respectively (Polychronis et al, 2005). These findings suggest a direct antiproliferative effect of gefitinib in this untreated breast cancer patient population.

In summary, the results of this study suggest that treatment with gefitinib in combination with docetaxel is a potentially active and well-tolerated regimen in untreated patient with MBC. A clinically relevant issue is the identification of potential predictive factors, which could help to select breast cancer patients who could respond to anti-EGFR targeted therapies. The results of this study suggest that women with ER-positive tumours have a higher RR and are most likely the patients that could benefit from the docetaxel plus gefitinib combination. However, further clinical translational research studies are necessary to define the role of gefitinib alone and/or in combination with docetaxel in the management of this subset of MBC patients.

\section{REFERENCES}

Albain K, Elledge R, Gradishar W (2002) Open-label, phase II, multicenter trial of ZD1839 ('Iressa') in patients with advanced breast cancer. Breast Cancer Res Treat 76(Suppl. 1): S33 (abstr.)

Baselga J, Tripathy D, Mendelsohn J, Baughman S, Benz CC, Dantis S, Sklarin NT, Seidman AD, Hudis CA, Moore J, Rosen PP, Twaddell T, Henderson IC, Norton L (1996) Phase II study of weekly intravenous recombinant humanized anti-p185HER2 monoclonal antibody in patients with HER2/neu-overexpressing metastatic breast cancer. J Clin Oncol 14: $737-744$

Baselga J, Albanell J, Ruiz A, Lluch A, Gascón P, Guillém V, González S, Sauleda S, Marimón I, Tabernero JM, Koehler MT, Rojo F (2005) Phase II antitumour and pharmacodynamic study of gefitinib in patients with advanced breast cancer. J Clin Oncol 23: 5323-5333

Bissery MC, Nohynek G, Sanderink GJ, Lavelle F (1995) Docetaxel (Taxotere $($ ) ): a review of preclinical and clinical experience. Part I: preclinical experience. Anticancer Drugs 6: 339-368

Bonneterre J, Roche H, Monnier A, Guastalla JP, Namer M, Fargeot P, Assadourian S (2002) Docetaxel vs 5-fluorouracil plus vinorelbine in metastatic breast cancer after anthracycline therapy failure. $\mathrm{Br} \mathrm{J}$ Cancer 87: $1210-1215$
Burris III HA (2001) Docetaxel (Taxotere) plus trastuzumab (Herceptin) in breast cancer. Semin Oncol 28: $38-44$

Ciardiello F, Caputo R, Bianco R, Damiano V, Somatico G, De Placido S, Bianco AR, Tortora G (2000) Antitumor effect and potentiation of cytotoxic drugs activity in human cancer cells by ZD-1839 (Iressa), an epidermal growth factor receptor-selective tyrosine kinase inhibitor. Clin Cancer Res 6: 2053-2063

Ciardiello F, Caputo R, Borriello G, Del Bufalo D, Biroccio A, Zupi G, Bianco AR, Tortora G (2002) ZD1839 ('Iressa'), an EGFR-selective tyrosine kinase inhibitor, enhances taxane activity in bcl-2 overexpressing, multidrug-resistant MCF-7 ADR human breast cancer cells. Int J Cancer 98: $463-469$

Ciardiello F, Tortora G (2001) A novel approach in the treatment of cancer: targeting the epidermal growth factor receptor. Clin Cancer Res 7: $2958-$ 2970

Esteva FJ, Valero V, Booser D, Guerra LT, Murray JL, Pusztai L, Cristofanilli M, Arun B, Esmaeli B, Fritsche HA, Sneige N, Smith TL, Hortobagyi GN (2002) Phase II study of weekly docetaxel and trastuzumab for patients with HER-2-overexpressing metastatic breast cancer. J Clin Oncol 20: $1800-1808$ 
Fleming TR (1982) One-sample multiple testing procedure for phase II clinical trials. Biometrics 38: 143-151

Fox SB, Smith K, Hollyer J, Greenall M, Hastrich D, Harris AL (1994) The epidermal growth factor receptor as a prognostic marker: results of 370 patients and review of 3009 patients. Breast Cancer Res Treat 29: $41-49$

Greenberg PA, Hortobagyi GN, Smith TL, Ziegler LD, Frye DK, Buzdar AU (1996) Long-term follow-up of patients with complete remission following combination chemotherapy for metastatic breast cancer. J Clin Oncol 14: 2197-2205

Grunwald V, Hidalgo M (2003) Developing inhibitors of the epidermal growth factor receptor for cancer treatment. J Nat Cancer Inst 95: $851-867$

Herbst RS, Fukuoka M, Baselga J (2004) Gefitinib, a novel targeted approach to treating cancer. Nat Rev Cancer 4: 956-965

Hortobagyi GN (2002) Can we cure limited metastatic breast cancer? J Clin Oncol 20: 620-623

Luetteke NC, Qiu TH, Fenton SE, Troyer KL, Riedel RF, Chang A, Lee DC (1999) Targeted inactivation of the EGF and amphiregulin genes reveals distinct roles for EGF receptor ligands in mouse mammary gland development. Development 126: 2739-2750

Kaplan EL, Meier P (1958) Non parametric estimation from incomplete observations. J Amer Statist Assoc 53: 457 -481

Klijn JG, Berns PM, Schmitz PI, Foekens JA (1992) The clinical significance of epidermal growth factor receptor (EGF-R) in human breast cancer: a review on 5232 patients. Endocr Rev 13: 3-17

Klijn JG, Look MP, Portengen H (1994) The prognostic value of epidermal growth factor receptor (EGFR) in primary breast cancer: results of a 10 year follow-up study. Breast Cancer Res Treat 29: 73-83

Knowlden JM, Hutcheson IR, Jones HE, Madden T, Gee JMW, Harper ME, Barrow D, Wakeling AE, Nicholson RI (2003) Elevated levels of epidermal growth factor receptor/c-erbB2 heterodimers mediate an autocrine growth regulatory pathway in tamoxifen-resistant MCF-7 cells. Endocrinology 144: $1032-1044$

Marty M, Cognetti F, Maraninchi D, Snyder R, Mauric L, Tubiana-Hulin M, Chan S, Grimes D, Anton A, Llunch A, Kennedy J, O' Byrne K, Conte P, Grenn M, Ward C, Mayene K, Extra JM (2005) Randomized phase II trial of the efficacy and safety of trastuzumab combined with docetaxel in patients with epidermal growth factor receptor 2-positive metastatic breast cancer administered as first-line treatment: the M77001 study group. J Clin Oncol 23: 4265-4274

Matsui Y, Halter SA, Holt JT, Hogan BL, Coffey RJ (1990) Development of mammary hyperplasia and neoplasia in MMTV-TGF alpha transgenic mice. Cell 61: 1147-1155

Mendelsohn J, Baselga J (2003) Status of epidermal growth factor receptor antagonists in the biology and treatment of cancer. J Clin Oncol 21: $2787-2799$

Mincey BA, Perez EA (2004) Concise review for clinicians: advances in screening, diagnosis and treatment of breast cancer. Mayo Clin Proc 79: $810-816$

Montemurro F, Choa G, Faggiuolo R, Donadio M, Minischetti M, Durando A, Capaldi A, Vietti-Ramus G, Alabiso O, Aglietta M (2004) A phase II study of three-weekly docetaxel and weekly trastuzumab in HER2overexpressing advanced breast cancer. Oncology 66: 38-45

Montero A, Fossella F, Hortobagyi G, Valero V (2005) Docetaxel for treatment of solid tumors: a systematic review of clinical data. Lancet Oncol 6: 229-239

Nabholtz JM, Gligorov J (2005) Docetaxel in the treatment of breast cancer: current experience and future prospectives. Expert Rev Anticancer Ther 5: $613-633$

Nabholtz JM, Senn HJ, Bezwoda WR, Melnychuk D, Deschenes L, Douma J, Vandenberg TA, Rapoport B, Rosso R, Trillet-Lenoir V, Drbal J, Molino A, Nortier JW, Richel DJ, Nagykalnai T, Siedlecki P, Wilking N, Genot JY, Hupperets PS, Pannuti F, Skarlos D, Tomiak EM, Murawsky M, Alakl M, Aapro M (1999) Prospective randomized trial of docetaxel versus mitomycin plus vinblastine in patients with metastatic breast cancer progressing despite previous anthracycline-containing chemotherapy. J Clin Oncol 17: 1413-1424
Nicholson RI, Hutcheson IR, Harper ME, Knowlden JM, Barrow D, McClelland RA, Jones HE, Wakeling AE, Gee JM (2002) Modulation of epidermal growth factor receptor in endocrine-resistant, estrogenreceptor-positive breast cancer. Ann N Y Acad Sci 963: 104-115

O'Shaughnessy J, Miles D, Vukelja S, Moiseyenko V, Ayoub JP, Cervantes G, Fumoleau P, Jones S, Lui WY, Mauriac L, Twelves C, Van Hazel G, Verma S, Leonard R (2002) Superior survival with capecitabine plus docetaxel combination therapy in anthracycline-pretreated patients with advanced breast cancer: phase III trial results. J Clin Oncol 20: $2812-2823$

Polychronis A, Sinnett HD, Hadjiminas D, Singhal H, Mansi J, Shivapatham D, Shousha S, Jiang J, Peston D, Barrett N (2005) Preoperative gefitinib versus gefitinib and anastrozole in postmenopausal breast cancer patients with oestrogen receptor-positive and epidermal growth factor receptor-positive primary breast cancer: a double-blind placebocontrolled phase II randomised trial. Lancet Oncol 6: 383-391

Ringel I, Horwitz SB (1991) Studies with RP 56976 (Taxotere): a semisynthetic analogue of taxol. J Natl Cancer Inst 83: 288-291

Robertson JF, Gutteridge E, Cheung KL, Owers R, Koehler M, Hamilton L, Gee J, Nicholson RI (2003) Gefitinib (ZD1839) is active in acquired tamoxifen (TAM)-resistant oestrogen receptor (ER)-positive and ERnegative breast cancer: Results from a phase II study. Prom Am Soc Clin Oncol 22, (abstr. 23)

Riou JF, Naudin A, Lavelle F (1992) Effects of Taxotere on murine and human tumor cell lines. Biochem Biophys Res Commun 187: 164-170

Salomon DS, Brandt R, Ciardiello F, Normanno N (1995) Epidermal growth factor-related peptides and their receptors in human malignancies. Crit Rev Oncol-Hematol 19: 183-232

Sandgren EP, Luetteke NC, Qiu TH, Palmiter RD, Brinster RL, Lee DC (1990) Overexpression of TGF alpha in transgenic mice: induction of epithelial hyperplasia, pancreatic metaplasia, and carcinoma of the breast. Cell 61: 1121-1135

Shou J, Masserweh S, Osborne CK, Wakeling AE, Ali S, Weiss H, Schiff R (2004) Mechanisms of tamoxifen resistance: increased estrogen receptorHER2/neu cross-talk in ER/HER2-positive breast cancer. J Natl Cancer Inst 96: $926-935$

Sirotnak FM, Zakowsky MF, Miller VA, Scher HI, Kris MG (2000) Efficacy of cytotoxic agents against human tumor xenografts is markedly enhanced by coadministration of ZD1839 (Iressa), an inhibitor of EGFR tyrosine kinase. Clin Cancer Res 6: 4885-4892

Sjöström J, Blomqvist C, Mouridsen H, Pluzanska A, Ottosson-Lönn S, Bengtsson N-O, stenstad B, Mjaaland I, Palm-Sjövall M, Wist E, Valvere V, Anderson H, Bergh J (1999) Docetaxel compared with sequential methotrexate and 5-fluorouracil in patients with advanced breast cancer after anthracycline failure: a randomised phase III study with crossover on progression by the Scandinavian Breast Group. Eur J Cancer 35: $1194-1201$

Tabernero J, Climent MA, Lluch A, Albanell J, Vermorken JB, Barnadas A, Antón A, Laurent C, Mayordomo JI, Estaun N, Losa I, Guillem V, GarciaConde J, Tisaire JL, Baselga J (2004) A multicenter randomized phase II study of weekly or 3-weekly docetaxel in patients with metastatic breast cancer. Ann Oncol 15: 1358-1365

Tedesco KL, Thor AD, Johnson DH, Shyr Y, Blum KA, Goldstein LJ, Gradishar WJ, Nicholson BP, Merkel DE, Murrey D, Edgerton S, Sledge Jr GW (2004) Docetaxel combined with trastuzumab is an active regimen in HER-2 3+ overexpressing and fluorescent in situ hybridization-positive metastatic breast cancer: a multi-institutional phase II trial. J Clin Oncol 22: $1071-1077$

Therasse P, Arbuck SG, Eisenhauer EA, Wanders J, Kaplan RS, Rubinstein L, Verweij J, Van Glabbeke M, van Oosterom AT, Christian MC, Gwyther SG (2000) New guidelines to evaluate the response to treatment in solid tumors :European Organization for Research and Treatment of Cancer, National Cancer Institute of the United States, National Cancer Institute of Canada. J Natl Cancer Inst 92: 205-216

von Minckwitz G, Jonat W, Fasching P, du Bois A, Kleeberg U, Lück HJ, Kettner J, Hilfrich J, Eiermann W, Torode J, Schneeweiss A (2005) A multicentre phase II study on gefitinib in taxane- and anthracyclinepretreated metastatic breast cancer. Breast Cancer Res Treat 89: 165-172 